\title{
Guided Online Case Scenarios Support Development of Clinical Decision-Making Skills in Speech-Language Pathology Master's Students
}

\author{
Krystal L. Werfel \\ University of South Carolina, werfel@sc.edu \\ Gabriella Reynolds \\ University of South Carolina, gir1@email.sc.edu \\ DOI: https://doi.org/10.30707/TLCSD4.2/ZHV05761
}

Follow this and additional works at: https://ir.library.illinoisstate.edu/tlcsd

Part of the Scholarship of Teaching and Learning Commons

\section{Recommended Citation}

Werfel, Krystal L. and Reynolds, Gabriella (2020) "Guided Online Case Scenarios Support Development of Clinical Decision-Making Skills in Speech-Language Pathology Master's Students," Teaching and Learning in Communication Sciences \& Disorders: Vol. 4: Iss. 2, Article 1.

DOI: https://doi.org/10.30707/TLCSD4.2/ZHV05761

Available at: https://ir.library.illinoisstate.edu/tlcsd/vol4/iss2/1 


\title{
Guided Online Case Scenarios Support Development of Clinical Decision-Making Skills in Speech-Language Pathology Master's Students
}

\begin{abstract}
Flipped classrooms are increasingly recommended by scholars of teaching and learning, and some have argued that active learning is the key ingredient in this model's success. This paper describes the creation and implementation of online guided case study scenarios using the test function of a learning management system, as well as evaluation of their effectiveness based on (a) performance of students on separate graded case study assignments and (b) student self-reflection of learning and feedback elicited in an end-of-course survey. The case studies were developed for use in a master's level speechlanguage pathology course on aural rehabilitation that occurs during the summer semester.
\end{abstract}

\section{Keywords}

active learning, flipped classroom, case scenarios, clinical decision making 


\section{Introduction}

The master's degree in speech-language pathology prepares students to embark on a career that involves extensive clinical decision-making. As more students access this training at least partially online, there is a need for research that evaluates methods of training clinical decision-making in an online context. This paper describes the creation and implementation of online guided case study scenarios using the test function of a learning management system, as well as evaluation of their effectiveness based on (a) performance of students on separate graded case study assignments and (b) student self-reflection of learning and feedback elicited in an end-of-course survey. The case studies were developed for use in a master's level speech-language pathology course on aural (re)habilitation that occurs during the summer semester.

The course utilized a "flipped classroom," or inverted classroom, philosophy (Lage, Platt, \& Treglia, 2000). At a basic level, flipped classrooms are classrooms that invert the traditional locations of learning activities, such that lecture now occurs outside the classroom and application activities take place inside the classroom (Bishop \& Verleger, 2013; Lage et al., 2000). Flipped classrooms additionally have been further described as learning environments with three primary characteristics: (a) information-transmission is moved outside of the classroom, to be completed before class, (b) class time is used for active and social learning, and (c) students complete outside of class activities before and after class to benefit fully from in-class learning activities (Abeysekera \& Dawson, 2015).

Importantly, the flipped classroom philosophy promotes the use of active learning activities to encourage students to engage with content using higher-level cognitive manipulation, including critical thinking, analysis, and synthesis of information (Bonwell \& Eison, 1991). This student engagement, importantly, is not related simply to introducing activity instead of lecture, but instead relies on the ability of that activity to engage students to create deep understanding of the topic at hand (Prince, 2004). The present study evaluated the utility of online guided case scenarios as such an activity.

Online guided case scenarios have been proposed as an active online learning activity for adult learners (Phillips, 2005). Used extensively with distance education nursing students, online guided case scenarios provide students the opportunity to actively engage in constructing knowledge while minimizing information overload, situating learning in a real-world context, and encouraging reflective learning (Johnson \& Aragon, 2003). Online guided case scenarios can minimize information overload by breaking down a clinical decision-making process into its component steps and present only part of the information at a time. Additionally, online guided case scenarios situate learning in a real-world context by providing actual clinical cases experienced by instructors to illustrate concepts covered in the course. Finally, online guided case scenarios can encourage reflective learning by including a student self-reflection as the final step in completion of the learning activity.

\section{Learning Context}

The course described here is a graduate-level course focused on aural habilitation and aural

rehabilitation. The students are master's students in speech-language pathology who have 
completed two semesters of coursework and clinical practicum rotations. In this course, we build on the knowledge gained from previous coursework on language and literacy acquisition/disorders, speech sound disorders, and audiology, with a particular focus on implementing evidence-based principles of intervention and assessment for individuals with hearing loss. During the first two times I taught this course, the students' performance on weekly and summative assessments indicated mastery of basic concepts but difficulty with applying these concepts to clinical scenarios. Therefore, I sought an instructional technique with efficacy for increasing application of knowledge to real-world situations.

\section{Weekly Structure of Course}

This course consisted of primarily weeks that contained an online module and in-class meeting. Due to scheduling constraints, three weeks of the course occurred completely online.

During the online module + in-class meeting weeks, students completed online modules that consisted of assigned readings, brief video lectures, online videos, active learning activities, and a self-check quiz (information-transmission). Each online module was designed to take two to four hours to complete prior to attending class. Students then came to in-class meetings that lasted two to three hours. In-class meetings were devoted solely to high-level active learning activities, and each meeting followed roughly the same agenda (active and social learning).

During the in-class meetings, students first were free to ask questions they had from the online modules. These questions were limited to helping students understand the material at a deep level, and questions about information that was answered during completion of these modules were not allowed. Second, an active learning activity took place. Examples of these activities included watching testimonials of individuals with hearing loss and/or their family members and discussing how their experiences related to material from the modules, having a debate about our state's Early Hearing Detection and Identification Act, and completing a language sample analysis of a child with hearing loss. After the active learning activity, students split off into small groups to complete in-class case study scenarios (described below). Finally, each class ended with an analysis of one type of online resource used in the module that week (e.g., TED talks, online webinars provided by Central Institute for the Deaf or AudiologyOnline, series of parent training videos).

After class the students completed a weekly case study assignment, which consisted of four short answer questions, designed to take one hour to complete. Students additionally completed an online quiz that provided automated feedback after attending the in-class session (post-class activity). These case study assignments were graded and served as an outcome measure in the analysis for this paper. Students did not receive a grade for the quiz but lost 0.5 points off their final grade if they did not complete it.

The total time devoted to course activities (online module, in-class meeting, and post-class assignments) was approximately 9 hours per week for the 3 -credit course. The course lasted for one full-term semester.

\section{Traditional In-Class Small Group Case Study Scenarios}


For the five hybrid sections of the course, small groups of four to five students completed in-class case study scenarios. Appendix A contains an example small group case scenario. The information was presented all at one time. Students were randomly assigned to different groups each week. Students were in the small groups for 15 - 20 minutes. Following small group discussions, one random student in each group was assigned to present their responses to the case study question(s) to the class. The instructor gave feedback to each group in the larger class setting, and students were able to ask questions and/or make comments about other groups' decision making. No grade was earned for completing this activity.

\section{Development of Online Guided Case Study Scenarios}

For the three weeks of the course that did not hold an in-class meeting, students completed online modules that contained the active learning activities that would have occurred during in-class meetings. Some researchers in the scholarship of teaching and learning have argued that the active ingredient of the flipped classroom is not the location of the learning (i.e., informationtransmission at home, active learning in person), but rather the presence of active learning itself (e.g., Jensen, Kummer, \& Godoy, 2015). In our own field, Baker (2011) highlighted the importance of relevancy in designing active learning activities. Therefore, during weeks that did not include an in-class meeting, the students completed online modules that were longer than on weeks with an in-class meeting. These modules followed the same model of students first completing information-transmission activities, then completing the active learning, i.e., the online guided case scenarios of interest in this paper. The case studies were specifically designed to be relevant to clinical cases that speech-language pathologists (colleagues or myself) have actually encountered in clinical practice. During these weeks students also completed a weekly assignment following completion of the information-transmission and active learning activities.

Using the test function of our learning management system (Blackboard), guided case study scenarios were created for two sections of the course that did not involve an in-class meeting. One guided case study scenario consisted of 6 questions, and one consisted of 8 questions (see Appendix B for example). Each scenario consisted of a combination of multiple choice and short answer questions. Questions were presented one at a time, and students received written feedback immediately after submitting each question. This format of the online guided case scenarios allowed more information to be presented about the case than the in-class case studies. No grade was earned for completing this activity.

\section{Student Feedback and Performance}

To evaluate the effectiveness of the online guided case studies, two methods of evaluation were utilized. First, an anonymous feedback survey specific to the guided online case studies was distributed to students at the end of the semester, for which they received extra credit in the course. Second, students in the course completed weekly graded case study assignments after completing either the in-class or online case study. Grades on the case study assignment from one section that 
involved guided online case studies ${ }^{1}$ were compared to grades on the case study assignment from one random other section that involved in-person case studies. This section were selected by inputting each eligible week into a Microsoft Excel file and using the random function [=RAND()]. After randomization, the top entry was selected as the comparison section.

Student feedback. Thirty-one of the thirty-two students $(97 \%)$ enrolled in the course completed the anonymous feedback survey. Of these students, six respondents commented generally about the course rather than specifically addressing the online guided case studies. These responses were judged by an independent faculty member to be general to the course rather than specific to the guided case studies and were removed from analysis. The specific student comments in response to open-ended questions about the guided online case scenarios are included in Appendix C.

Several themes emerged from the student provided feedback. Interestingly, the sentiments differed between the in-class and online case studies. Most students responded that regarding the in-person case studies, they found to be most helpful the opportunities to collaborate with colleagues and hear multiple perspectives on a given problem. Some also reported that they valued the opportunity to learn from their peers and the in-class assignment served as an example for the online case studies. When asked about what they did not find helpful from these in-class assignments the students cited amount of class time devoted to them, and the often-repetitive nature of the whole class discussion at the end where the groups presented their responses. When answering what aspects of the online case studies the students found to be most helpful, themes that emerged included the sequential systematic presentation of the case study, the feedback provided along the way and how the assignment allowed them to synthesize information learned from readings with clinical scenarios. Many students did not have any negative comments about the online case studies. In fact, many requested more of them during the semester. Some students did report that they would have preferred overall tailored feedback or the opportunity to discuss, similar to the in-class assignments.

Students were also asked to rate the following two comments on a 100-point scale: 1 . The in-class small-group case scenario activities were helpful to my understanding of the course material. 2. The online Blackboard step-by-step case scenario activities were helpful to my understanding of the course material. For statement 1, regarding the in-class activities, the average rating was 71.52 ( $\mathrm{SD}=17.79$ ), and for statement 2 , regarding the guided online case scenarios, the average rating was 80.44 ( $\mathrm{SD}=13.43)$. A paired-sample $t$-test indicated that student self-rating of learning for the two activities was significantly different, $p=.033$, and Cohen's $d$ effect size analysis indicated a medium effect $(d=0.566 ; 95 \% \mathrm{CI}=0.001-1.131)$.

Student grades. Each post-class case study assignment (described above in Weekly Structure of the Course) was worth a total of 5 points. Importantly, these assignments were separate from the in-class case study activity or the online guided case scenario, neither of which were graded. The graded assignments covered the same general topics as the in-class or online case scenarios because they occurred in the same week of the course, but the specific case details and questions

\footnotetext{
${ }^{1}$ One of the sections that included guided online case studies involved a weekly assignment that differed from the typical case study assignment (i.e., review of an online auditory training program) and was therefore not included in this comparison.
} 
asked were different. This assignment consisted of four clinical questions and was completed by students after finishing the entire weekly module. On the graded assignment from the week with the guided online case scenario, students earned an average score of 4.93 (SD $=0.25$; range $=4-$ 5). On the graded assignment from the week that included an in-class case scenario, students earned an average score of $4.04(\mathrm{SD}=0.84$; range $=1.5-5)$. A paired-sample $t$-test indicated that the performance on the two assignments was significantly different, $p<.001$, and Cohen's $d$ effect size analysis indicated a large effect $(d=1.436 ; 95 \% \mathrm{CI}=0.887-1.986)$. The median, and mode, performance on the former assignment was 4 and on the latter was 5. Therefore, students performed higher on an assessment of their clinical decision-making skills following the guided online case study than a traditional in-class discussion.

\section{Conclusion}

Overall, the student feedback and student grade data converged to suggest that guided online case scenarios are beneficial for integrating active learning into master's level speech-language pathology coursework. One goal of the online guided case scenarios was to encourage critical thinking while scaffolding students to construct knowledge while minimizing information overload (Johnson \& Aragon, 2003). Overwhelmingly, students reported that their self-perception of clinical decision-making skill development was higher following the step-by-step case scenarios than the group in-class case study activities. The aspect of the guided case scenarios that students found most helpful was breaking down the decision-making process into steps with feedback along the way, aligning with the principle encouraged by Johnson and Aragon to minimize information overload. This component could be easily implemented in in-person case scenarios as well. Consistent with Jensen et al. (2015), it appears that the active ingredient of learning here may be the structure, rather than the modality, of the guided online case scenarios. Instructors in master's level speech-language pathology programs can be confident that scaffolding clinical decisionmaking in a step-by-step guided process can increase student performance and student selfperception of learning, which may be particularly helpful for distance learning programs.

In the future, I have two immediate plans to revise the guided case scenarios based on student feedback. First, I will implement a follow-up discussion board for each scenario to give students the opportunity to discuss their responses and ask each other questions, simulating an in-class discussion. I will monitor these discussions and provide guidance as necessary. Second, I will integrate videos into the online guided case scenarios to provide a more realistic experience than just reading information about a case.

\section{Author Disclosures}

Krystal L. Werfel receives a salary from the University of South Carolina and has received an Innovative Pedagogy Grant from the University of South Carolina Center for Teaching Excellence to integrate videos into the online guided case scenarios.

Gabriella Reynolds is a doctoral student and receives funding from the University of South Carolina. 


\section{References}

Abeysekera, L., \& Dawson, P. (2015). Motivation and cognitive load in the flipped classroom: Definition, rationale, and a call for research. Higher Education Research \& Development, 34, 1-14. doi: 10.1080/07294360.2014.934336

Baker, K. F. (2011). Active learning: Relevancy matters. SIG 10 Perspectives on Issues in Higher Education, 14, 64-69. doi: 10.1044/ihe14.2.64

Bishop, J. L., \& Verleger, M. A. (2013). The flipped classroom: A survey of the research. Proceedings of the $120^{\text {th }}$ ASEE Annual Conference. Accessed from https://www.asee.org/public/conferences/20/papers/6219/view.

Bonwell, C., \& Eison, J. (1991). Active learning: Creating excitement in the classroom. ASHEERIC Higher Education Report No. 1. Washington, DC: George Washington University.

Jensen, J., Kummer, T., \& Godoy, P. (2015). Improvements from a flipped classroom may simply be the fruits of active learning. CBE-Life Sciences Education, 14, 1-12. doi:10.1187/10.1187/cbe.14-08-0129

Johnson, S., \& Aragon, S. (2003). An instructional strategy framework for online learning environments. New Directions for Adult and Continuing Education, 100, 31-43.

Lage, M.J., Platt, G.J., \& Treglia, M. (2000). Inverting the classroom: A gateway to creating an inclusive learning environment. The Journal of Economic Education, 31, 30-43. doi: $10.2307 / 118333$

Phillips, J. (2005). Strategies for active learning in online continuing education. The Journal of Continuing Education in Nursing, 36, 77-83. doi: 10.3928/0022-0124-20050301-08

Prince, M. (2004). Does active learning work? A review of the research. Journal of Engineering Education, 93, 223-231. doi: 10.1002/j.2168-9830.2004.tb00809.x 


\section{Appendix A}

\section{Example In-Class Case Study Activity}

\section{Section: Auditory Development and Training (4 versions)}

a. Erber's Auditory Hierarchy, or Listening Ladder, describes four stages of auditory development. Your group has been assigned sound detection*. Using this rung of the Listening Ladder, identify a goal on the Auditory Learning Guide to target with your client. Give your client a name, an age, and a case history (of your choosing), and use the General Principles for Auditory Training to develop a lesson plan (one treatment activity) to target your chosen goal. You may use these resources, but you may not use internet resources such as Pinterest to develop your treatment activity. The person who will present your activity to the class is the person who arrived to class latest tonight.

*Other groups were assigned sound discrimination, sound identification, and sound comprehension. 


\section{Appendix B}

\section{Example Guided Online Case Scenario}

\section{Auditory Training - Adults Online Guided Case Scenario Instructions}

Using Blackboard's "Test" function, you will walk through a case scenario related to auditory training for adults. Don't worry, though. You will not receive a grade; instead, this is an active learning activity. You will see questions one at a time, and each new question will build on the case from the previous. You will be able to view all your responses and correct answers at the end of completion. There are 8 total questions.

\section{Question 1 (Multiple Answer)}

Lucy is a fifty-year-old judge who has just received hearing aids for the first time. She has had progressive hearing loss for about ten years, and during her last trial, she decided that it was time to make some changes so that she could perform her duties effectively. To her audiologist, Lucy specifically reported that she finds it difficult to hear witness testimony because her location prevents her from being able to see their mouths when they talk and almost impossible to understand recorded evidence (e.g., phone call recordings). During the last trial, she realized just in time that she was going to make an incorrect ruling based on her inability to hear a piece of the evidence. She is enthusiastic about completing auditory training with her new devices, even though her audiologist said that it was optional.

First, select each of the following that are components of auditory training for adults.

\section{Answer: \\ sound awareness \\ sound perception \\ speech perception \\ language comprehension}

Correct Feedback: That's right: Auditory training for adults consists of three components: sound awareness training (the detection of the presence or absence of sound), sound perception training (recognizing pitch, loudness, and duration of nonspeech sounds), and speech perception training (recognizing speech in a variety of listening contexts).

Incorrect Feedback: Auditory training for adults consists of three components: sound awareness training (the detection of the presence or absence of sound), sound perception training (recognizing pitch, loudness, and duration of nonspeech sounds), and speech perception training (recognizing speech in a variety of listening contexts).

\section{Question 2 (Short Answer)}

Auditory training for adults consists of three components

1. sound awareness training 
2. sound perception training

3. speech perception training

Consider Lucy's previous complaints about her hearing and the attached audiogram. In addition to the information reported on the audiogram, the audiologist noted that when tested in background noise at a +10 SNR, Lucy's speech recognition scores dropped to 50\% in each ear. Taking all of this information into account, at which level of auditory training would you focus your efforts and why?

\{The audiogram displays a mild sloping to moderately severe bilateral sensorineural hearing loss\}

Answer: I would focus the majority of my efforts on speech perception training for Lucy. Although she has had hearing loss for approximately 10 years, it has been progressive so she hasn't been without auditory input for a long period of time. There's nothing in her reported history that would lead us to believe that she needs training detecting the presence or absence of sound. As you progress through aural rehabilitation, it is possible that you will uncover some difficulties with pitch, loudness, or duration of nonspeech sounds, but there is nothing in the case history so far that suggests that sound perception is the primary area of difficulty. Rather, when you consider Lucy's specific complaints about difficulty understanding people whose faces she cannot see and auditory information presented over recordings, it is most logical to expect speech perception training to be the area of need and the area of most potential for gains in treatment.

\section{Question 3 (Short Answer)}

I would focus the majority of my efforts on speech perception training for Lucy. Although she has had hearing loss for approximately 10 years, it has been progressive so she hasn't been without auditory input for a long period of time. There's nothing in her reported history that would lead us to believe that she needs training detecting the presence or absence of sound. As you progress through aural rehabilitation, it is possible that you will uncover some difficulties with pitch, loudness, or duration of nonspeech sounds, but there is nothing in the case history so far that suggests that sound perception is the primary area of difficulty. Rather, when you consider Lucy's specific complaints about difficulty understanding people whose faces she cannot see and auditory information presented over recordings, it is most logical to expect speech perception training to be the area of need and the area of most potential for gains in treatment.

Now that you have decided to focus on speech perception training, you have three hierarchies of difficulty to consider. First let's think about the noise hierarchy. Based on Lucy's audiologic report, at which level of the noise hierarchy would you begin therapy and why?

Answer: I would begin at white noise. Lucy's audiogram shows strong speech (word) recognition scores in quiet, but her audiologist reported that her performance dropped to 50\% with a +10 SNR. Therefore, noise causes increased difficulty for Lucy. The report did not include information about what kind of noise was used, so I would initially start with white noise and increase the difficulty as necessary. 


\section{Question 4 (Short Answer)}

I would begin at white noise. Lucy's audiogram shows strong speech (word) recognition scores in quiet, but her audiologist reported that her performance dropped to $50 \%$ with a $+10 \mathrm{SNR}$. Therefore, noise causes increased difficulty for Lucy. The report did not include information about what kind of noise was used, so I would initially start with white noise and increase the difficulty as necessary.

Now you have established your entry point in the noise hierarchy. Now it's time to decide the difficulty level in the utterance length hierarchy. The audiologist also reported speech recognition scores for sentences and common phrases: sentences: $85 \%$ in quiet, $65 \%$ in noise; common phrases: $85 \%$ in quiet, $60 \%$ in noise. Combining this information with what you already know about words, at what point in the utterance length hierarchy would you being therapy and why?

Answer: Given that we have established the need to work in noise (question 3) and Lucy's complaints about hearing-related difficulties at her job (question 1), I would begin at the easiest level of the listening hierarchy: sentences. It is likely that Lucy will progress quickly through this area, particularly with hearing aids and move into higher levels of utterance length difficulties after as little as just one session.

\section{Question 5 (Short Answer)}

Given that we have established the need to work in noise (question 3) and Lucy's complaints about hearing-related difficulties at her job (question 1), I would begin at the easiest level of the listening hierarchy: sentences. It is likely that Lucy will progress quickly through this area, particularly with hearing aids and move into higher levels of utterance length difficulties after as little as just one session.

Now we have determined our levels in the noise hierachy: white noise, as well as the utterance length hierarchy: sentences. The final level of difficulty to determine is the contextual difficulty hierarchy. Given Lucy's current level of functioning, at what contextual difficulty level would you begin therapy and why?

Answer: I would begin at the bridge set difficulty level in terms of context for Lucy. As a judge, she generally knows the topic being discussed and training at this level will likely have the most ecological validity for her.

\section{Question 6 (Short Answer)}

I would begin at the bridge set difficulty level in terms of context for Lucy. As a judge, she generally knows the topic being discussed and training at this level will likely have the most ecological validity for her.

You have identified the noise, utterance length, and contextual difficulty hierarchies for your initial treatment target for Lucy. Before writing your goals, there's one more decision to make. Auditory stimuli can be presented in live voice or via a device (e.g., recorder, phone). How will you present the auditory stimuli and why? 
Answer: Given the complaints Lucy presented with, I would perform auditory training for Lucy using live voice with no visual cues (like witnesses), as well as via recordings (like recorded evidence).

\section{Question 7 (Short Answer)}

Given the complaints Lucy presented with, I would perform auditory training for Lucy using live voice with no visual cues (like witnesses), as well as via recordings (like recorded evidence).

Now you have all the information you need to write goals for Lucy. Write two goals here.

Answer: Remember, goals should contain three components: a "do" statement, a "context" statement, and a "criterion" statement. Here are two example goals that I might write for Lucy.

1. Lucy will identify sentences in a bridge set presented via live voice with no visual cues with $90 \%$ accuracy.

2. Lucy will identify sentences in a bridge set presented via audio recording with $90 \%$ accuracy.

Your goals do not have to be exactly like mine. Go back and evaluate the goals you wrote. First, do they each have a "do" statement? (Mine are bolded above). Second, do they each have a "context" statement? (Mine are underlined above). Third, do they each have a "criterion" statement? (Mine are italicized above). Finally, have you chosen targets that align with the three difficulty levels that are most appropriate for Lucy?

\section{Question 8 (Short Answer)}

Remember, goals should contain three components: a "do" statement, a "context" statement, and a "criterion" statement. Here are two example goals that I might write for Lucy.

1. Lucy will identify sentences in a bridge set presented via live voice with no visual cues with $90 \%$ accuracy.

2. Lucy will identify sentences in a bridge set presented via audio recording with $90 \%$ accuracy.

Your goals do not have to be exactly like mine. Go back and evaluate the goals you wrote. First, do they each have a "do" statement? (Mine are bolded above). Second, do they each have a "context" statement? (Mine are underlined above). Third, do they each have a "criterion" statement? (Mine are italicized above). Finally, have you chosen targets that align with the three difficulty levels that are most appropriate for Lucy?

The last step in this case scenario training module is to reflect on your learning. Write about what you learned by completing this active learning activity. Things to consider writing about (but don't limit yourself to this list):

What did I previously think that I understood but had difficulty applying it to a case scenario? What content knowledge is more solidified after applying it? 
What misconceptions did I have?

What areas do I still find difficult?

How do I see myself applying these skills with clients? 


\section{Appendix C}

\section{Student Feedback - Unedited Comments}

\section{Please tell me what you found most helpful about the online Blackboard case scenarios.}

Step-by-step layout allowed me to check my answers

I could concentrate better on the question at hand and usually it's immediately after finishing the module which was helpful.

I like how it helped us make the transition from learning information to using information. The case scenarios definitely helped me think critically about important concepts and helped me shape my thoughts into functional clinical decision-making processes.

I found these to be super helpful. I really like how each question led to the next, and once I provided my answer and went to the next question, the appropriate response was provided for me. This allowed me to compare my answer with the correct/appropriate one, and I would say "oh i forgot about that" or "oh i didn't think to say it like that, but that makes sense."

It helped me fully understand what I was learning prior to attempting the case study assignment. They also clarified information I did not understand and give me a different perspective on how you would have answered it. They were practical.

I liked that feedback was provided immediately for each question.

I did like seeing how you can progress from start to finish with one case history. It helped tie everything from the module together.

I was able to relate what I learned in the modules to how the information will actually affect me, not just mindless memorization.

They really helped me to apply knowledge gained from the Perusall readings and online modules.

I can see how the case scenarios should be very beneficial, but I honestly felt like by the time I got to them, I was just typing things out and clicking through in order to be done.

I like that they went step by step kind of through the whole process. They were an overall case study more so than the in-class case scenarios. I felt like with the online ones we really went through the whole process which was helpful. Having an example answer on the next page was really helpful to figure out how I was doing on them.

It was helpful to complete these case scenarios on our own time and at the completion of the online module material. In addition, I appreciated that we were prompted with the correct responses at the beginning of the next section. This allowed us to check our progress and move forward with the next question.

I could work at my one pace and problem solve through the activity.

I thought the Blackboard case scenarios were a good opportunity to talk myself through clinical application of the material as I was typing it out. It acted as a self-quiz - as opposed to the more discussion based case scenarios in class.

It further engrained what I learned in the module and gave me an opportunity to test my knowledge and learn from my mistakes.

They let me know that I was on the right track with learning the material for the week. I liked how you provided the answers for the previous questions. I liked how they were similar to the case studies questions because then I knew that my answers for the real case study were likely to be correct. 
I liked that you could receive feedback after each step so that you could apply the correct information moving forward. That way, the time spent on it felt productive and like I was actively learning, not just taking a quiz and failing.

I like that the correct answers were provided after we submitted each question. This way, if you gave a wrong answer for one step of the case study, it would not throw you off for the entire thing.

I liked that sample answers were provided in the subsequent questions. This helped guide my learning if I was unsure about an answer for another question or topic.

I liked that the blackboard case scenarios only allowed you to reflect on on part before moving on to the next. I was less overwhelmed by the questions and it provided a more logical way of attacking the scenario. I liked the feedback provided on your part after submitting my answer.

The blackboard case scenarios were helpful in allowing me to see how much information I had obtained through the online lecture. It also is helpful as a clinician to be given a case and have to work through it along with selecting what word choice is most appropriate in a given situation. The immediate feedback was great (your answer) once you went on to the next question. Your reasoning for the answer was there and helped re-evaluate or affirm my answer.

The online case scenarios were excellent! It was very helpful to work through real-life cases step by step. It was also beneficial to receive immediate feedback on each step.

These helped me answer the pointless case studies.

\begin{tabular}{l}
\hline Please tell me what you found least helpful about the online Blackboard case scenarios. \\
\hline Overall they were more helpful than they were not helpful \\
\hline only one per module and not being every week \\
\hline It would be helpful to see your work afterward to review and compare for corrections etc. \\
\hline Sometimes it is difficult to go through the clinical decision-making process without actually \\
having a real person to speak to and make observations of. \\
\hline \begin{tabular}{l} 
I found them very helpful, but once i figured out that the right answer would be on the next page, \\
I was urged to skip to the next question to read the right answer. I didn't do this because that's \\
not how I learn, it wouldn't be helpful for me in the long run, and not to mention it wasn't for a \\
grade. I suggest turning on the feature where you're not able to go back to the previous question \\
for the case scenarios, so that eliminates the possibility that people can skip to the next question \\
to read the right answer. \\
\hline $\begin{array}{l}\text { N/A- I found these to be helpful in immediately applying the material we had just learned in the } \\
\text { module. }\end{array}$ \\
\hline $\begin{array}{l}\text { I wish we would have had more examples to refer to. I ended up working through it, but then } \\
\text { missing information and going back through. I think with more models this could have been } \\
\text { extremely beneficial. }\end{array}$ \\
\hline N/A \\
\hline They were time consuming. And during a summer semester like this one when I barely have \\
time to complete them in the first place, I feel as though I am not able to give them my all. If \\
they were implemented during a less work-heavy semester, I would have been able to put more \\
time and cognitive effort into their completion. \\
They felt like just another thing on top of all the other things, so I didn't put as much time and \\
effort into them as I should.
\end{tabular} \\
\hline
\end{tabular}


Overall I really found all aspects helpful. I think they were the most helpful part of the modules for synthesizing the information.

$\mathrm{n} / \mathrm{a}$

I preferred the Blackboard case scenarios to the in-class version, and I think the only way in which the opposite was true was that the in-class case scenarios received feedback for answers. The sample answers on Blackboard were helpful, but in cases where my answers were different but not necessarily wrong, I would've liked feedback similar to the in-class scenarios. $\mathrm{n} / \mathrm{a}$

It would be nice if the general case history could be included for every question because I had to keep going back to question 1 to re-look at the information.

I honestly found them very helpful and can't think of a specific negative to list. I think having more of them may be beneficial!

It would be nice to see all the parts of the case study at one time. Sometimes I would move on to the next question and I did not remember what I had put down as my previous answer. It would be nice to have more than one case scenario per topic just for practice purposes.

N/A

I feel like they were helpful but maybe after have a discussion board going with others in the class to talk through them?

n/a - I thought they were very helpful

n/a. I found them extremely helpful! 